\title{
Enjoyable e-Learning Modules: Developing and Evaluating
}

\author{
Qabas Abdal Zahraa Jabbar \\ Department of Computer Sciences, \\ College of Science, \\ Al-Mustansiriyah University. \\ Baghdad, Iraq
}

\begin{abstract}
This paper focuses on developing an important kind of elearning Modules (eLMs) which is enhanced with fun and enjoyment. However such kind is suitable with children in primary school or pre-primary school. A case study has presented during developing and evaluating. Many papers have been published on designing and evaluating eLMs. A systematic model has been considered in designing eLMs. However this kind of learning is enhanced with fun and enjoyment . Visual interface programming technique is used to introduce eLMs. Multimedia represents the core of presented material in eLMs. Sound, video, images, text and animated objects are all included accordingly. After completing the eLMs a case study has been applied on the topic of ( Learning English Letters \& numbers).final conclusion ensuring the effective role of multimedia in expressing elements of fun \& enjoyment also the positive impression of children and teachers who tried the modules. Also it has been ensured That eLMs are friendly learning tool.
\end{abstract}

\section{Keywords}

(e-Learning Modules) eLMs , enjoyable , Visual Programming, Friendly Learning Tool

\section{INTRODUCTION}

Due to the extending and growing of e-Learning, many teaching institutions applied this important technology. For kids and pre-primary schools the major domain deals with games and fun applications. The proposed modules depend on a systematic model of Teaching/Learning process via eLearning. However the mentioned model realized maximization of the instructional outcomes as well as ensuring the meaningful/effective learning. The authors did not express more details about teaching/Learning process because the target of this paper deals with computer science, visual programming and multimedia domain. In Evaluating process selected criteria of evaluating related with Software Engineering are considered.

\section{OBJECTIVE OF RESEARCH}

The current research aims at :

1. Developing a system for e-Learning modules this system was designed depending on standard approach of eLMs with enjoyment and fun.

2. Applying the needful system to introduce experimental eLMs.

3. Evaluate the experimental eLMs according to the technical criteria regarding fun and enjoyment as well as some selected factors of Instructional S/W engineering modules.

\section{THEORETICAL BACKGROUND 3.1.Authoring System}

The concept of authoring system deals with developing a master software, this developed software tool can introduce several e-learning modules for any given topic by the instructor.

The idea of authoring system deals with development two main projects, the first user is the instructor who may enter his material ( text, exam, pictures, exercise, voice files, video clip files, etc ) according to the instructions of the system. This master software in the first project can generate multiple types of ELMs to satisfy the instructor requirements. All the entry material would be saved and transformed into the second project ( student project ). Then it would be reconstructed via student's project. The student will find an ideal systematic e-Learning module in his project ( second project ) according to the type of e-Learning module selected by the instructor and according to the entry material by the instructor.

\section{2.e-Learning Modules.}

ssss In the presented study, we shall consider the following main types of eLMs which exhibit some similarity with existing conventional learning systems. However there are many methods of eLMs but the researcher selected standard 8 major methods as shown
a. Tutorial Method (Text Presentation).
b. Drill \& Practice Method (Exercises)
c. .Problem Solving Method
d. Testing (e-Exam Method)
e. Instructional Games
f. Simulation
g. Dialog
h. Intelligent learning

The previous conventional learning methods are described as follows:-

\section{a. Tutorial}

In this type of learning, the purpose is to present a new instructional material or to promote current instructional skills of the candidate. So, to achieve such a purpose, there are some steps should be executed according to the following steps:

Introduction $\rightarrow$ tutorial section $\rightarrow$ present information $\rightarrow$ question and answer session $(Q \& A) \rightarrow$ feedback or immediate response 


\section{b. Drill \& Practice}

For this type of learning approach, the main purpose is to practicing and enhancement of skills of the learning mind, particularly to grasp the information by solving different exercises e.g. foreign language learning.

\section{Output of tutorial lesson $\rightarrow$ input of Drill and Practice} lesson.

Accordingly, to achieve such objective, there are major steps should be implemented given by the following:

Introduction $\rightarrow D \& P$ section $\rightarrow$ select item $\rightarrow Q \& A \rightarrow$ Score $\rightarrow$ closing $\rightarrow$ feedback. Drill and Practice method is suitable for solving problems and practicing exercises like mathematics, statistics.

\section{c. Problem Solving Method}

This learning approach having a target of testing the student's skills of problem, solving logic and ability to follow direction (algorithm). Primarily used to augment higher order of thinking skills, so it may activate brain storming of learner.

\section{d. Testing Method :}

This method depends mainly on making a quiz where Quiz is designed to test the knowledge or achievement of subjects by learners. To let them know which questions were missed and what the correct answers were (score can be seen immediately). So, achieving such goal requires implementing the following steps:

The output of all lessons (tutorials, drill and practice, etc) and classroom $\rightarrow$ input of test lesson. However there are five kinds of e-exam: multiple choices, matching between words in two columns, fill in blanks, Yes or No and answer in one word.

e. Instructional games The main purpose of this approach is to provide an environment that facilitates learning or acquisition of skills. Games however or may not mimic reality. This approach has a major advantage of existing a fun of use and learning under light environment. Achieving this goal imply executing the following steps:
Introduction $\rightarrow$ game section $\rightarrow$ presentation $\rightarrow$ scenario $\rightarrow$ action required $\rightarrow$ closing $\rightarrow$ score $\rightarrow$ system updates $\rightarrow$ student action.

f. Instructional Simulation Method : This approach is based on Learning by performing activity similar to real world, useful while learning to use complicated difficult to obtain, expensive machine or pieces of equipment also better used for dangerous activities. Simulation contains an effective mathematical model to process the input data of the learner. The required steps to implement this method are shown in the following diagram.

g. Dialog Method : However this method requires wide experiences of the instructor who planes for dialog method regarding designing the communication between computer and candidate, it depends that candidate would discover the instructional objectives of the lesson without expressing directly the instructional material. Needs professional skills and long time, but realizing concentrate learning skills.

h. Intelligent learning : This approach of e-Learning depends on Artificial Intelligent concept and application like searching within instructional knowledge base system. This technique may be used for physical disabled persons.

\section{THE PROPOSED SYSTEM}

The following diagram represents the system which is enhanced with fun and enjoyment

The proposed system represents an authoring system which allows the instructor to submit his own learning material which is enhanced with enjoyment and fun. Those factors of enjoiyment and fun could be represented by multimedia files , video, flash , sound, colors, text , animation and images .

Therefore enjoiyment and fun are the major requirements of eLMs which will expected to be generated by the system.

In the next couple of pages , an experimental eLM which was introduced by the system will be presented as case study in the research. Later stage of this research is to evaluate the experimented eLM accordingly. 


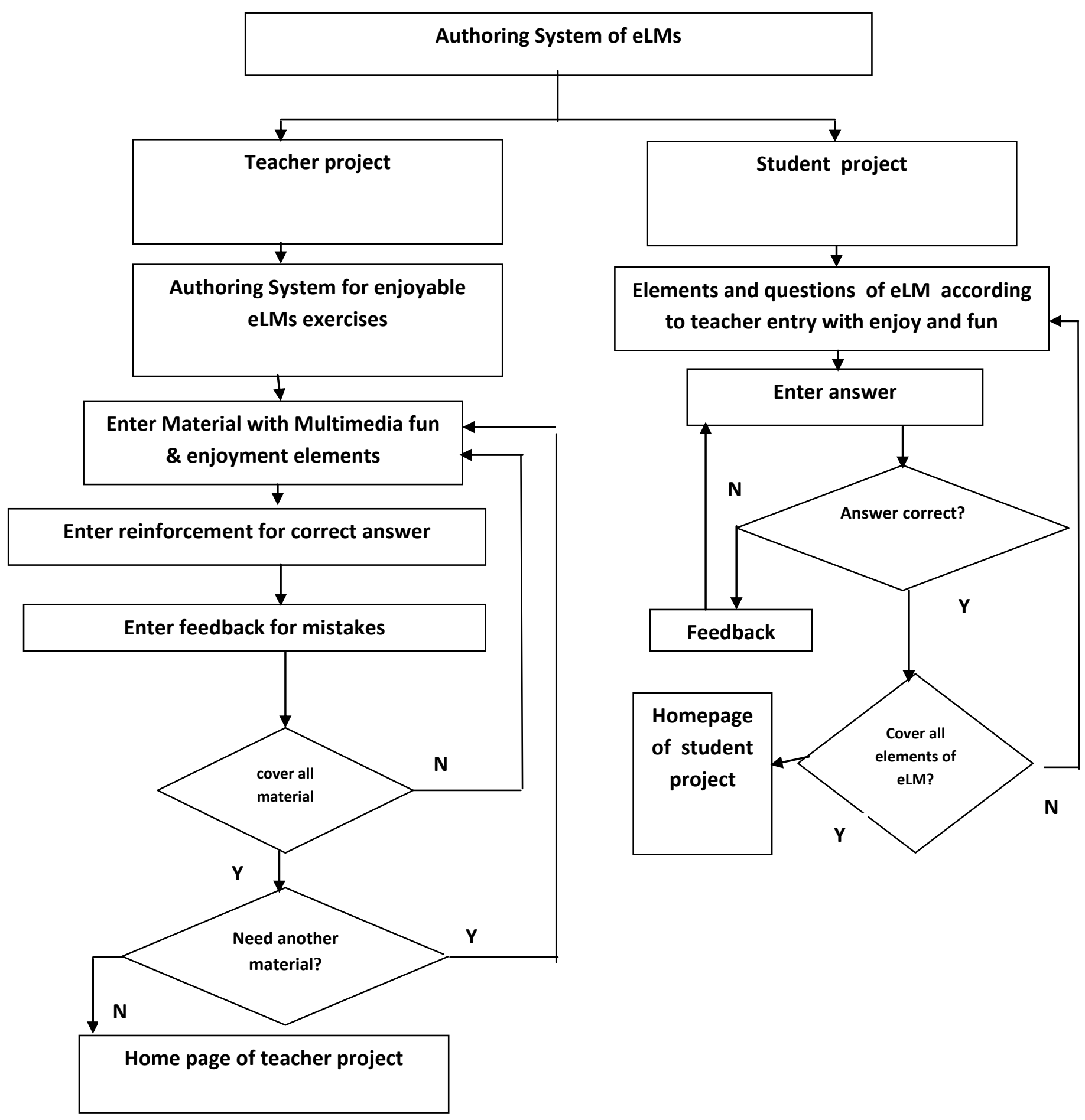

Fig.1 Block Diagram of the Authoring System 


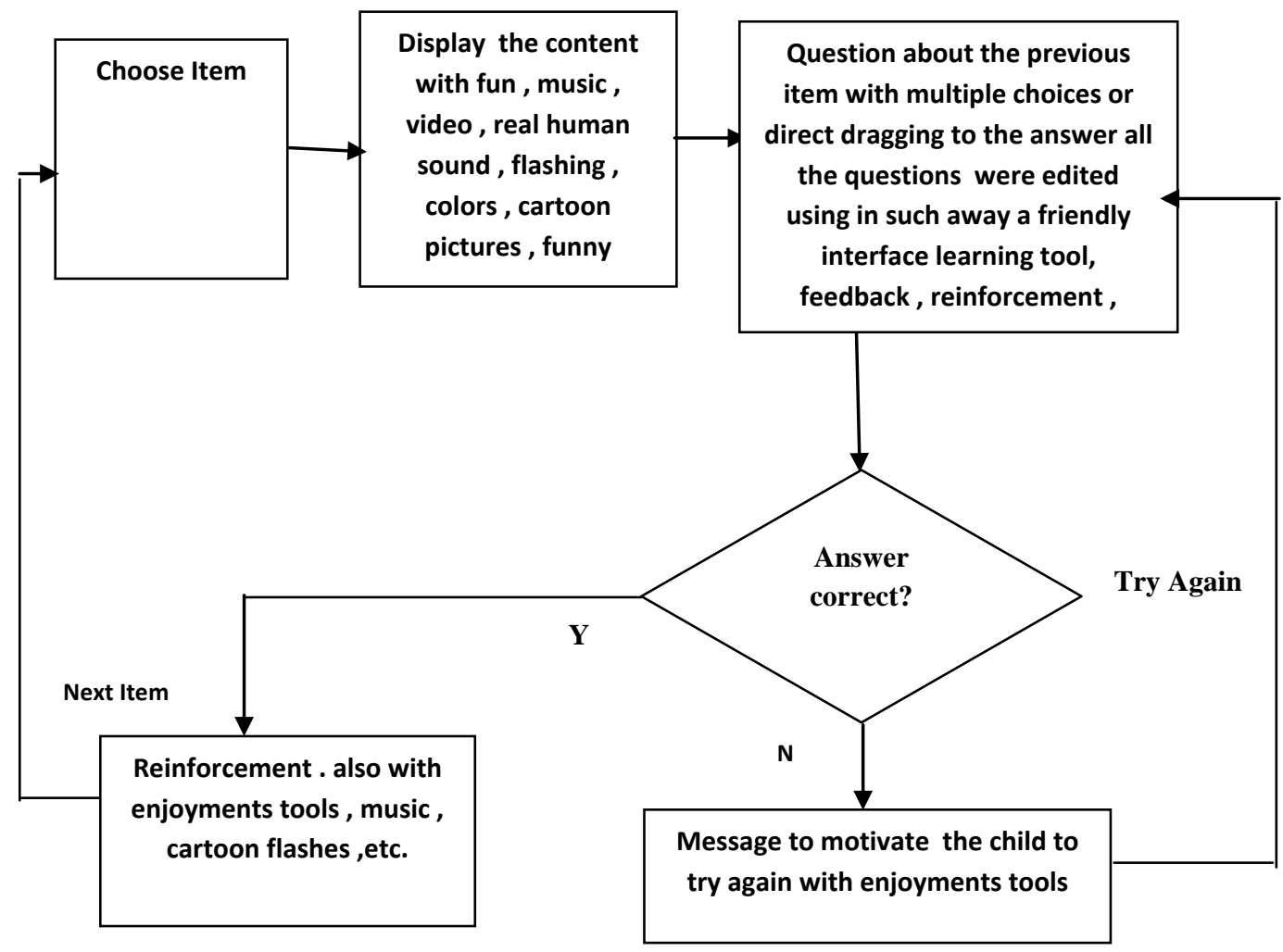

Fig.2 Block Diagrams of General Enjoyable Module

However Visual Programming is used with multimedia components. Also database is used to save submission information by the instructor. Some selected child sounds and kids are included too. The case study which is considered was about learning English letters and figures because the oriented children are Arab, therefore English language represents foreign language.
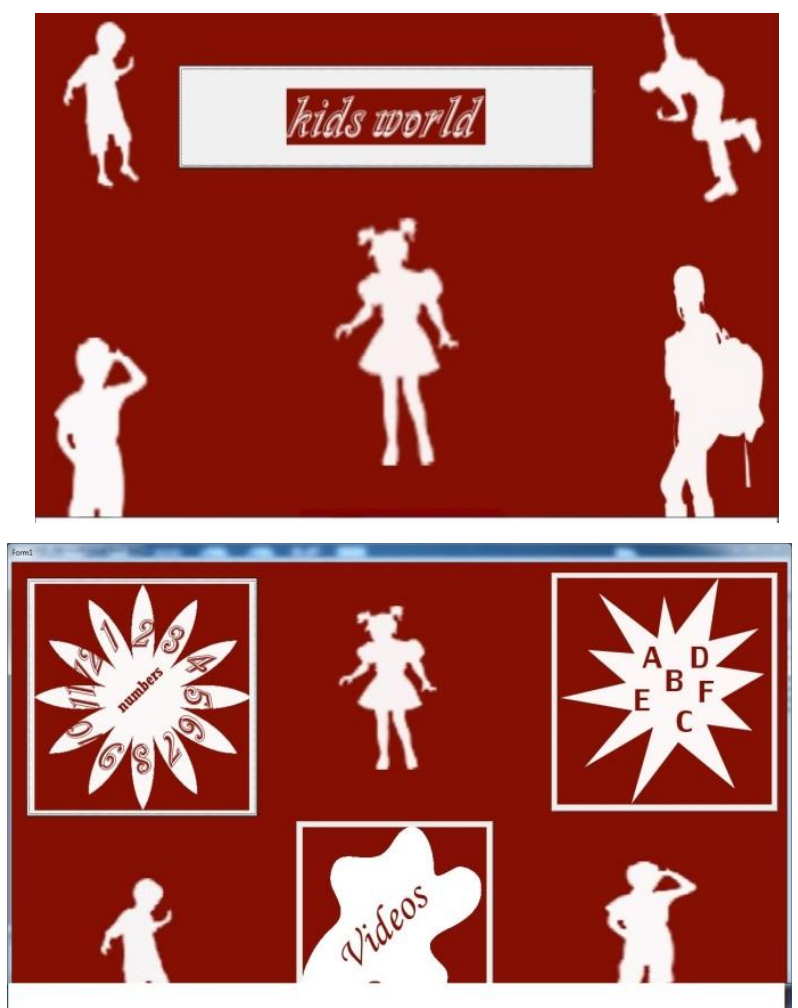
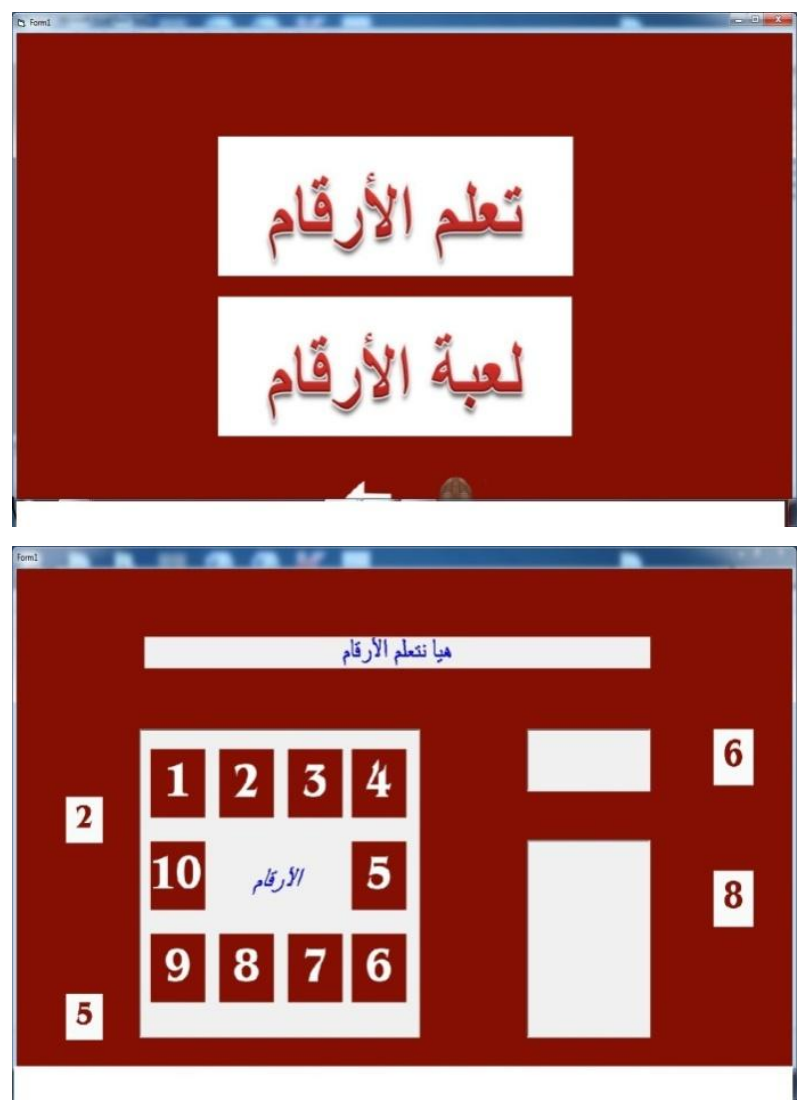


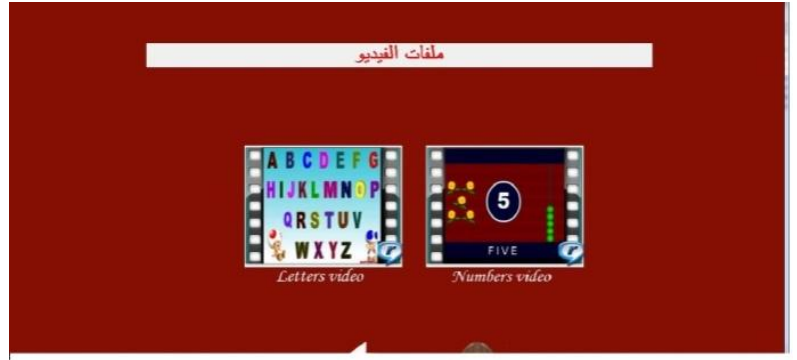

Fig.3 Sequence of Print-Out screens for Experimental elearning Module

\section{EVALUATION ISSUES}

Some selected items of criteria are considered regarding elements of fun and enjoyment. However those criteria were selected from a previous research by the author too.

The mentioned criteria of evaluation were followed below with its regarding section of the experimental module.

\subsection{Instructional Computer Criteria [1]}

eLM method[7] : Regarding this criterion, as written above there are 8 major methods for introducing eLMs, in the current research, the selected method should enhanced with fun \& enjoyment however such method is either Instructional Game method or Tutorial method. The selected case study is tutorial method mixed with some kind of Gaming method and enhanced with elements of fun \& enjoyment.

\subsection{Output Criteria [1]}

i. Visual \& Audio features and Multimedia criteria [11]

There are 5 ideal sub-criteria for Visual \& Audio features as well as 5 ideal sub-criteria for general Multimedia processes. About Visual \& Audio criteria, they deal with: "Font should be clear, big size, color in opposite to background .

- Colors should be clear, suitable with subject and without high brightness.

- Backgrounds should be free from pictures and without visual noise. Also they must in simple and clear colors.

- Visual and audio noise is important factor because all the instructional material. Therefore all images, pictures, diagrams, charts, texts, labels, video clips, sound files ,etc they all must be free from noise. As less as possible of colors, simplified pictures and diagrams clear and meaningful sound. Besides it is better to use simple and friendly pictures ,images. “ [1]

About Multimedia process, Also there are some criteria as follow" Multimedia represents the core of eLMs. Therefore it is very important to design technique of multimedia so that to realize the needful goals of eLMs.

- Size of pictures which display clips must be suitable size and in clear colors (human engineering) so that the action could be easily recognized by the student.

- Speed of presenting video clips must be slow so that to be easily traced and understood by the student.

- The student can repeat playing his desired cuts of video as well as sound files.
- As per previous items, eLMs are to be presented in multiple modes of communication to cover all categories/levels of students. Multimedia technique must support such multiple-modes. Therefore it is recommended that multimedia is to be flexible an effective to support displaying video clips, real voice files of characters in clips , picture files besides text of each word of that clip or picture

- Flashing of object is important for some commands to guide the student for next instructional task." [1]

- Due to the pervious items, the experimental eLMs in the current paper are matching with those criteria.

\subsection{Software development Criteria [1]}

i. Computer Algorithms : eLMs in the case study sound satisfactory towards algorithm criteria like not sizable of memory.

ii. database and data file managements : database represents an important aspect in the proposed system because the authoring system which introduces eLMs depends upon database. This criteria focuses on easy access to information of the eLMs.

iii. "S/W language should be of visual programming technique like Visual Basic.net" : Visual Basic and its multimedia components are used in introducing eLMs.

\subsection{General Criteria}

i. i. Output in each screen: as per rules of eLMs each of patch screen of output, it must represent on learning objective so as the learner can achieve target of eLM easily.

ii. Scheduled time for answering or entering data[5][7] it is better to allow learner learns with his own speed. It means realizes individualization of learning. In the experimental eLMs individualization was ensured.

\subsection{Fun and enjoyment [11]}

i. Friendly learning tool [11] : The experimental eLMs are friendly learning tool for the learners.

ii. Motivation criteria [9] : such friendly learning tools can enhance motivation of learners reading learning process.

iii. Attitudes : it is expected that such eLMs can match attitudes of learners towards learning.

\section{CONCLUSION AND FUTURE WORK 6.1 Conclusion}

The author summarized conclusion of the current paper within the few below lines.

Enjoyable eLMs are matching with the required criteria of designing and implementing e-Learning systems particularly for gaming method and tutorial method. Multimedia \& visual programming environment are the major tools which realize fun\& enjoyment features. Finally eLMs must be controlled by systematic criteria elements so as to achieve target of eLMs. 


\subsection{Future Work}

Many studies were selected to be future work for this research :

1. How to design and implement online-eLearning Modules via smart Mobile device includes all factors of fun \& enjoyment.

2. How to develop Enjoyable e-Learning Modules based on another e-learning methodology, like eGames, Problem Solving, Drill \& Practice and Intelligent Learning methods.

\section{REFERENCES}

[1] Qabas Abdal Zahraa Jabbar, "Evaluating Model for Elearning Modules According to Selected Criteria: An Object Oriented Approach", Computer and Information Science; Vol. 5, No. 5; 2012 , CANADA

[2] Dalia Sabri," Performance Analysis for Network Coding Using Ant Colony Routing", Master of Philosophy, Electronic and Computer Engineering, School of Engineering and Design, Brunel University, December, 2011

[3] Xiao-Min Hu and Jun Zhang,"Minimum Cost Multicast Routing Using Ant Colony Optimization Algorithm", Hindawi Publishing Corporation, Mathematical Problems in Engineering, Article ID 432686, 18April, 2013.

[4] Marco dorigo and Thomas stuzle Bradford company scituate,MA "Ant colony optimization ", USA 2004 ISBN: 0262042193

[5] Helio,J.C.Barbosa,Janeza"Ant colonyoptimizationtechniques and applications" Trdine9, 51000 Rijeka, Croatia, 2013.
[6] "Ant colony optimization - methods and applications" edited by Aviostfeld ISBN 978-953-307-157-2, Puplushed: February4, 2011 Under CC by-NC-SA3.0 License.

[7] C.W.Ahn,R.S.Ramakrishna,C.G.Kang.AndI.C.Choi."Sho rtestpath Routing algorithm using Hopfield Neural Network". Electron. Lett. Vol. 37 No. 19 PP. 1176-1178. Sept, 2001

[8] Aboul Ella Hassanien ,Eid Emary"Swarm intelligence: principles, advances , and application" by CRC Press referenc-210pages-25 B/M Ilustration ISBN78148741064-cat\#k26721. November 24,2015

[9] Computational intelligence methods and technique leszk ruttkowski, 2008.

[10] "Ant colony optimization" Edwin Wong, Phillip Summers, Rosalyn Ku, and Patrick Xie, PIC 10C Spring 2011.

[11] Important Links for e - Learning and Computer Assisted Instruction

[12] http://www.ceap.wcu.edu/houghton/learner/Look/CAI.ht $\mathrm{ml}$

[13] www.prel.org available at: Pacific Resources for Education and Learning

[14] http://www.wikipedia.org

[15] http://wikiindex.com/Wiki_Index

[16] http://www.world66.com/

[17] http://c2.com/cgi/wiki availableat: ContentCreationWiki

[18] http://wikitravel.org/en/ available at: welcome to Wikitravel 